\title{
PENGARUH PRODUK, HARGA, LOKASI DAN PROMOSI TERHADAP KEPUTUSAN PEMBELIAN KONSUMEN PADA DISTRO CLUB DI KOTA BOGOR
}

\author{
${ }^{1)}$ Benny Osta Nababan, ${ }^{2)}$ Jubaedi \\ ${ }^{1)}$ Dosen Program Studi Manajemen, STIE Dewantara \\ J1. Raya Pemda Bojong Depok Baru III, Karadenan, Cibinong, Bogor, Jawa Barat 16913, Indonesia \\ Email: benny.osta@dewantara.ac.id \\ ${ }^{2)}$ Alumni Program Studi Manajemen, STIE Dewantara \\ Jl. Raya Pemda Bojong Depok Baru III, Karadenan, Cibinong, Bogor, Jawa Barat 16913,Indonesia \\ Email: jiuaditya@gmail.com
}

\begin{abstract}
This study the sampling technique used accidental sampling technique and the samples of this study was 100 respondents. The results of the study show that the results of the partial hypothesis test prove that the product variable with a t-count value of 3,240>t-table value 1.66. With a significance value of $0.002<0.05$ a significance value smaller than 0.05 indicates that at the significance level of 5\%, the hypothesis $\mathrm{HO}$ is rejected and Ha is accepted. Hypothesis test results simultaneously prove that together the factors of product, price, location and promotion have a positive and significant influence on consumer purchasing decisions Distro Club Kota Bogor. The results of multiple linear regression test obtained a regression equation that is $Y=$ $5.743+0.399 X 1+0.187 X 2+0.010 X 3+0.081 X 4$ which means that there is an increase in product, price, location and promotion as much as one unit will raise consumer purchasing decisions Distro Club City of Bogor. Whereas if there is no increase in product value, price, location and promotion then the value of the consumer purchasing decision Distro Club Bogor City will be constant at 5.743. The results of the coefficient of determination test obtained an adjusted $R^{2}$ value of 0.290, this shows that 29.0\% purchasing decisions in Distro Club Bogor City influenced by the marketing mix while the remaining $71.0 \%$ purchasing decisions are influenced by other variables not examined in this research.
\end{abstract}

Keywords: Product, Price, Location, Promotion, Purchasing Decision.

\begin{abstract}
ABSTRAK
Dalam penelitian ini teknik pengambilan sampel menggunakan teknik accidental sampling dan jumlah sampel penelitian ini adalah 100 responden. Hasil penelitian menunjukan hasil uji hipotesis secara parsial membuktikan bahwa variabel produk dengan nilai t-hitung sebesar $3,240>$ nilai t-tabel 1.66. Dengan nilai signifikansi sebesar $0,002<0,05$ nilai signifikansi yang lebih kecil dari 0,05 menunjukkan bahwa pada taraf signifikansi 5\% maka hipotesis HO ditolak dan Ha diterima. Hasil uji regresi linier berganda diperoleh persamaan regresi yaitu $Y=5,743+$ $0,399 \mathrm{X} 1+0,187 \mathrm{X} 2+0,010 \mathrm{X} 3+0,081 \mathrm{X} 4$ yang artinya bahwa setiap ada peningkatan produk, harga, lokasi dan promosi sebanyak satu satuan akan menaikan keputusan pembelian konsumen Distro Club Kota Bogor. Sedangkan jika tidak ada kenaikan nilai produk, harga, lokasi dan promosi maka nilai keputusan pembelian konsumen Distro Club Kota Bogor akan konstan sebesar 5,743. Hasil dari uji koefisien determinasi diperoleh nilai adjusted $R^{2}$ sebesar 0,290, hal ini menunjukan bahwa 29,0\% keputusan pembelian di Distro Club Kota Bogor dipengaruhi oleh bauran pemasaran sedangkan sisanya $71,0 \%$ keputusan pembelian dipengaruhi oleh variabel-variabel lainnya yang tidak diteliti dalam penelitian ini.
\end{abstract}

Kata kunci: Produk, Harga, Lokasi, Promosi, Keputusan Pembelian. 


\section{PENDAHULUAN}

\subsection{Latar Belakang}

Peningkatan akan adanya distro di jaman modern ini mengakibatkan ketatnya per-saingan dalam bisnis ini. Sehingga menurut para pelaku bisnis untuk mampu memaksimalkan kinerja perusahaannya agar dapat bersaing di pasar.

Secara umum saat ini konsumen lebih memilih produk yang berharga murah namun memiliki kualitas yang baik, oleh sebab itu dengan kondisi persaingan bisnis yang sangat tinggi, para pelaku bisnis harus mampu memahami dan mengetahui keinginan dan kebutuhan konsumennya dan terus berinovasi untuk menciptakan posisiproduknya dengan baik dan memanfaatkan keunggulan-keunggulan yang ada pada produk yang ditawarkan. Menurut Cravens (2005) dalam Magda (2017), perusahaan yang gagal memahami kebutuhan, keinginan, selera dan proses keputusan pembelian konsumen akan mengalami kegagalan dalam pemasaran dan penjualannya.

Toko Distro Club sudah berdiri selama tiga tahun terakhir ini terus meningkat, yaitu dari tahun 2015 sampai dengan tahun 2017.

Data mengenai hasil penjualan tahunan di Distro Club Kota Bogor pada kurun waktu tiga tahun terakhir disajikan dalam tabel 1 sebagai berikut:

Tabel 1. Jumlah hasil penjualan Distro Club di Kota Bogor tahun 2015 -2017.

\begin{tabular}{|c|c|c|c|}
\hline No & Tahun & $\begin{array}{c}\text { Jumlah hasil } \\
\text { penjualan (Rp) } \\
\text { Tahun 2015-2017 }\end{array}$ & $\begin{array}{c}\text { Peningkatan } \\
(\%)\end{array}$ \\
\hline 1 & 2015 & $2,733,169,000$ & \\
\hline 2 & 2016 & $3,403,895,500$ & $19,7 \%$ \\
\hline 3 & 2017 & $3,553,152,500$ & $4,2 \%$ \\
\hline
\end{tabular}

Sumber : Data penjualan Distro Club di Kota Bogor, tahun 2015-2017.

\subsection{Tujuan Penelitian}

1. Mengetahui pengaruh produk, harga, lokasi dan promosi secara parsial ter- hadap keputusan pembelian konsumen

Distro Club di Kota Bogor.Mengetahui pengaruh produk, harga, lokasi dan promosi secara simultan ter-hadap keputusan pembelian konsumen Distro Club di Kota Bogor.

2. Mengetahui faktor-faktor yang paling dominan terhadap keputusan pembelian konsumen Distro Club di Kota Bogor.

\section{TINJAUAN PUSTAKA}

\subsection{Landasan Teori}

\subsubsection{Produk (X1)}

Menurut Kotler \& Amstrong (2008:75) dalam Ferania (2017), produk adalah segala sesuatu yang dapat ditawarkan kepasar untuk mendapatkan perhatian, dibeli, digunakan, atau konsumsi yang dapat memuaskan keinginan atau kebutuhan. Sedangkan Tjiptono (2008:65), telah mengungkapkan adanya delapan dimensi kualitas produk yang bisa dimainkan oleh pemasar yaitu, Quality, Durability, Conformance to Spesification, Features, Reability, Aesthetics, Percaived Quality dan Servicibility.

Indikator yang digunakan untuk variabel produk dalam penelitian ini adalah:

1. Kualitas produk

2. Daya tahan produk

3. Kesesuaian produk dengan spesifikasi

4. Estetika atau tampilan produk

\subsubsection{Harga (X2)}

Menurut Kolter dan Amstrong (2008:90) dalam Ferania (2017), harga adalah sejumlah uang yang ditagihkan atas suatu produk atau jasa, atau jumlah dari nilai yang ditukarkan para opelanggan untuk memperoleh manfaat dari memiliki atau mengunakan suatu produk atau jasa.

Dalam penelitian ini menggunakan empat indikator yang mencirikan harga yaitu Tjiptono (2008:110) dalam Ferania (2017).

1. Keterjangkauan harga 
2. Kesesuaian harga dengan kualitas produk

3. Harga yang ditawarkan beragam

4. Kesesuaian harga dengan manfaat produk

\subsubsection{Lokasi (X3)}

Menurut Kotler dan Amstrong (2008:121) dalam Ferania (2017), salah satun kunci sukses adalah lokasi. Lokasi dimulai dari komunitas, keputusan ini sangat bergantung pada potensi pertumbuhan ekonomi, stabilitas, persaingan, iklim politik, dan sebagainya. Dalam penelitian ini meng-gunakan empat indikator yang mempengaruhi sebuah lokasi tempat usaha, Mischitelli (2000) dalam Ferania (2017).

1. Lokasi penjualan yang strategis

2. Area parkir yang luas dan aman

3. Jangkauan akses menuju lokasi

4. Jarak pandang lokasi

\subsubsection{Promosi (X4)}

Menurut Kotler dan Amstrong (2008:345) dalam Ferania (2017), promosi adalah aktivitas yang menyampaikan manfaat produk dan membujuk pelanggan membelinya. Dalam penelitian ini menggunakan empat indikator yang mencirikan Promosi yaitu (Kottler \& Amstrong,2008) dalam Ferania (2017).

1. Hadiah

2. Potongan harga

3. Contoh barang

4. Informasi produk selalu tersedia

\subsubsection{Keputusan Pembelian (Y)}

Menurut Kottler ( 2007: 223) dalam Sidah (2016), keputusan pembelian adalah beberapa tahapan yang dilakukan oleh konsumen sebelum melakukan keputusan pembelian suatu produk. Dapat disimpulkan bahwa dalam mengambil keputusan memilih produk atau merek, konsumen akan melakukan proses terlebih dahulu, karena konsumen tidak mau menanggung risiko apabila membeli produk tersebut, sehingga konsumen akan penuh dengan pertimbangan sampai akhirnya konsumen mengambil keputusan pembelian.

Variabel terikat memiliki indikator sebagai berikut:

a. Pencarian informasi.

b. Penilaian alternatif.

c. Keputusan pembelian.

d. Prilaku setelah membeli

\subsection{Definisi Operasional.}

Tabel 2. Definini Operasional

\begin{tabular}{|c|c|c|c|c|}
\hline No & Variabel & $\begin{array}{c}\text { Landasan } \\
\text { Teori }\end{array}$ & Indikator & $\begin{array}{c}\text { Skala } \\
\text { Pengukuran }\end{array}$ \\
\hline 1 & $\begin{array}{l}\text { Produk } \\
\text { (X1) }\end{array}$ & $\begin{array}{l}\text { Tjiptono } \\
(2008: 65)\end{array}$ & \begin{tabular}{|l|}
$\begin{array}{l}\text { Kualitas } \\
\text { produk }\end{array}$ \\
Daya \\
tahan \\
produk \\
Kesesuaia \\
n produk \\
dengan \\
spesifikasi \\
Estetika \\
atau \\
tampilan \\
produk
\end{tabular} & $\begin{array}{c}\text { Skala Likert } \\
\text { (1-5) }\end{array}$ \\
\hline 2 & Harga (X2) & $\begin{array}{l}\text { Tjiptono } \\
\text { (2008:110) }\end{array}$ & \begin{tabular}{|l|}
$\begin{array}{l}\text { Keterjangk } \\
\text { auan harga }\end{array}$ \\
Kesesuaia \\
n harga \\
dengan \\
kualitas \\
produk \\
Harga \\
yang \\
ditawarkan \\
bragam \\
Kesesuaia \\
n harga \\
dengan \\
manfaat \\
produk
\end{tabular} & $\begin{array}{c}\text { Skala Likert } \\
(1-5) \\
\end{array}$ \\
\hline 3 & $\begin{array}{l}\text { Lokasi } \\
\text { (X3) }\end{array}$ & $\begin{array}{l}\text { Mischitelli } \\
\text { (2000) }\end{array}$ & \begin{tabular}{|l}
$\begin{array}{l}\text { Lokasi } \\
\text { penjualan }\end{array}$ \\
i yang \\
strategis \\
Area \\
parkir
\end{tabular} & $\begin{array}{c}\text { Skala Likert } \\
\quad(1-5)\end{array}$ \\
\hline
\end{tabular}




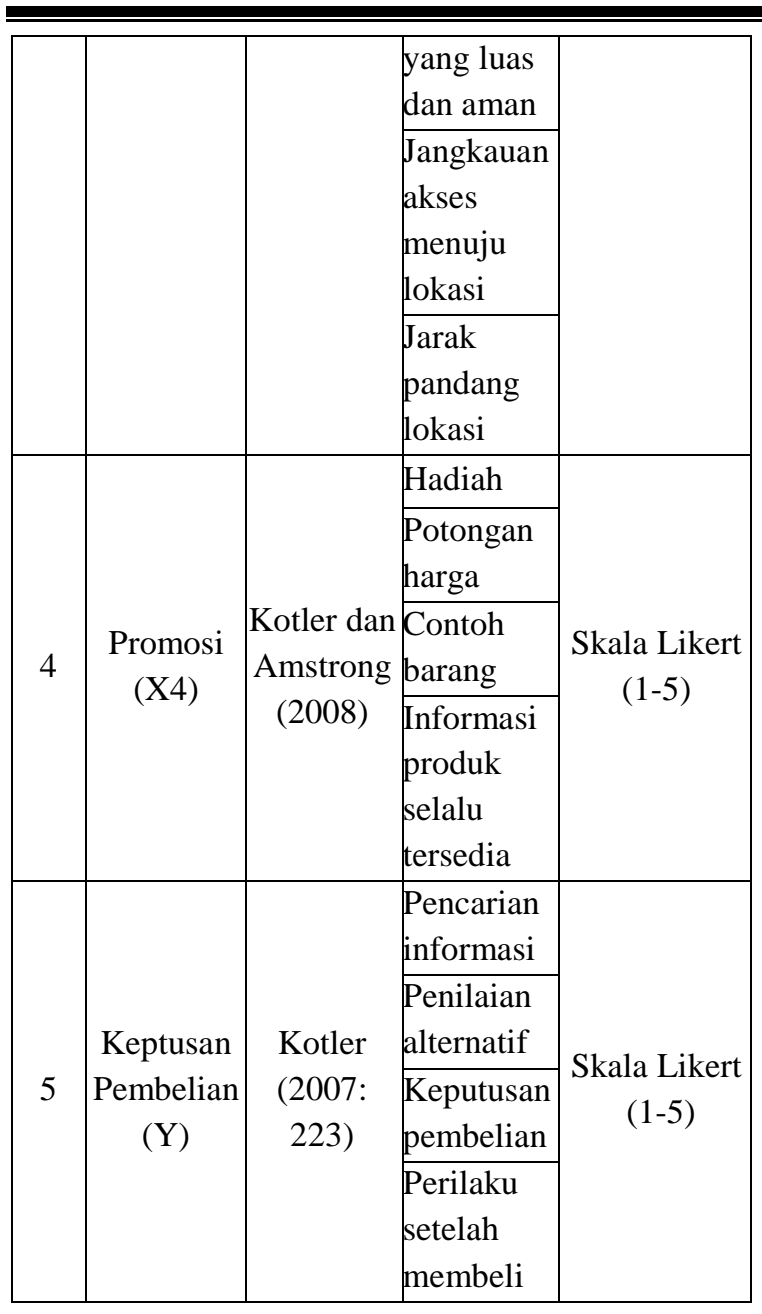

\subsection{Kerangka Pemikiran}

Adapun kerangka pemikiran dalam penelitian ini di sajikan dalam gambar 1 sebagai berikut:

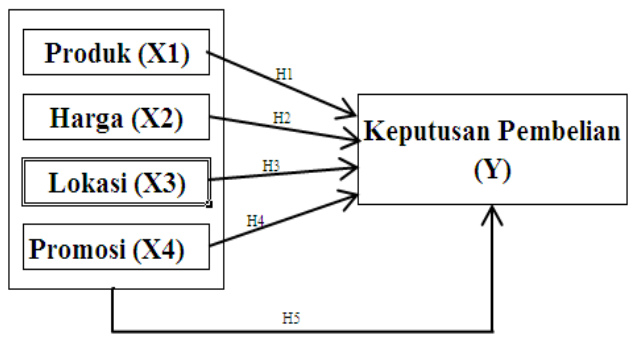

Gambar 1. Kerangka Pemikiran

\subsection{Hipotesis}

Hipotesis merupakan suatu ide untuk mencari fakta yang harus dikumpulkan. Hipotesis adalah suatu pertanyaan sementara atau dugaan yang paling memungkinkan yang harus masih dicari kebenarannnya.
Hubungan antar variabel dalam penelitian ini memiliki hipotesis sebagai berikut:

$\mathrm{H} 0$ : Tidak terdapat pengaruh antara produk (X1), harga (X2), lokasi (X3) dan promosi (X4) secara parsial dan simultan terhadap keputusan pembelian konsumen (Y).

$\mathrm{H} 1$ : Terdapat pengaruh antara produk (X1) secara parsial terhadap keputusan pembelian konsumen $(\mathrm{Y})$.

H2 : Terdapat pengaruh antara harga (X2) secara parsial terhadap keputusan pembelian konsumen $(\mathrm{Y})$.

H3 : Terdapat pengaruh antara lokasi (X3) secara parsial terhadap keputusan pembelian konsumen $(\mathrm{Y})$.

H4 : Terdapat pengaruh antara promosi (X4) secara parsial terhadap keputusan pembelian konsumen (Y).H5

Terdapat pengaruh antara produk (X1), harga (X2), lokasi (X3) dan promosi (X4) secara simultan terhadap keputusan pembelian konsumen (Y).

\section{METODE PENELITIAN}

\subsection{Jenis Penelitian}

Jenis penelitian ini termasuk dalam kategori penelitian kuantitatif kausalitas. Menurut Sugiyono (2003:11) penelitian kausal adalah penelitian yang bertujuan menganalisis hubungan sebab-akibat. Dalam hal ini adalah pengaruh produk, harga, lokasi dan promosi terhadap keputusan pembelian konsumen pada Distro Club di Kota Bogor.

\subsection{Variabel Penelitian}

Dalam penelitian ini ada dua variabel yang akan diteliti yaitu:

1. Variabel Independen atau Variabel Bebas Sugiyono (2001). Variabel independen/bebas adalah variabel yang mempengaruhi variabel lain atau yang menjadi sebab perubahannya atau timbulnya variabel dependen.

2. Variabel Dependen atau Variabel Terikat Sugiyono (2001). Variabel 
dependen/terikat adalah variabel yang mempengaruhi atau yang menjadi akibat karena adanya variabel bebas.

\subsection{Lokasi dan Waktu Penelitian}

Penelitian ini dilaksanakan di Distro Club yang beralamat di Jl Ciheuluet No 5 Pakuan Kota Bogor dan waktu penelitian ini dimulai pada bulan Maret sampai dengan bulan September 2018.

\subsection{Populasi dan Sampel}

\subsubsection{Populasi}

Menurut Sugiyono (2009 :80) yang dimaksud dengan populasi adalah wilayah generalisasi yang terdiri atas subyek atau objek yang mempunyai kualitas dan karakteristik tertentu yang ditetapkan oleh peneliti untuk dipelajari dan ditarik kesimpulannya. Populasi dalam penelitian ini adalah konsumen yang berbelanja atau yang pernah belanja di Distro Club di Kota Bogor yang jumlahnya tidak diketahui secara pasti. Hal ini karena Distro Club belum menggunakan sistem komputer untuk struk penjualan.

\subsubsection{Sample}

Menurut Sugiyono (2009:81) yang dimaksud dengan sampel adalahbagian dari jumlah dan karakteristik yang dimiliki oleh populasi tersebut. Dalam penelitian ini teknik pengambilan sampel diambil menggunakan teknik accidental sampling yaitu teknik penentuan sampel berdasarkan kebetulan, yaitusiapa saja yang secara kebetulan/accidental bertemu dengan peneliti saat berbelanjadi Distro Club dapat digunakan sebagai sampel, bila dipandang orang yang kebetulan ditemui cocok sebagai sumber data (Sugiyono, 2009:85).

Karena populasinya tidak diketahui secara pasti jumlahnya maka digunakan teknik atau rumus sesuai dengan teori Malhotra (2006:291) paling sedikit harus empat atau lima kali dari jumlah item pertanyaan. Indikator dalam penelitian ini terdiri dari empat variabel bebas dan satu variabel terikat. Total pertanyaan dalam penelitian ini adalah 20 pertanyaan, sehingga minimal ukuran sampel penelitian ini adalah:

$$
20 \times 5=100
$$

Jadi jumlah sampel penelitian ini adalah 100 orang/responden. Sampel dari penelitian ini adalah konsumen Distro Club di Kota Bogor.

Tabel 3. Skoring Item Instrumen

\begin{tabular}{|l|c|}
\hline \multicolumn{1}{|c|}{ Kategori } & Skor \\
\hline Sangat Setuju & 5 \\
\hline Setuju & 4 \\
\hline Kurang Setuju & 3 \\
\hline Tidak Setuju & 2 \\
\hline Sangat Tidak Setuju & 1 \\
\hline
\end{tabular}

Sumber : Sugiyono, 2006.

\subsection{Teknik Analisis Data}

Dalam menguji kebenaran suatu penelitian, dibutuhkan suatu teknik analisis yag tepat dan memadai. Pemilihan teknik analisis yang tepat akan memberikan suatu uji yang benar dan dapat dipercaya. Adapun analisis data yang digunakan dalam penelitian ini adalah Uji Validitas, Uji Reliabilitas, Uji Asumsi Klasik, Uji Korelasi, Uji Koefisien Determinasi $\left(\mathrm{R}^{2}\right)$, Analisis Regresi Linier Berganda dan Uji Hipotesis.

\section{HASIL DAN PEMBAHASAN}

\subsection{Gambaran Umum Objek}

\section{Penelitian Sejarah Perkembangan Distro} Club

Distro Club adalah salah satu distro yang berada di Kota Bogor yang berdiri pada tahun 2010, arti nama dari Distro Club sendiri adalah yang berarti tempat untuk mengintegrasikan dan mengumpulkan seluruh brand lokal dalam sebuah wadah yang diberi nama Distro Club.

Distro Club sampai saat ini sudah memiliki tiga toko yang berada di kota kota besar yaitu: 
1. Toko pertama beralamat di Jl. Ciheulet Pakuan No 05 Bogor.

2. Toko kedua beralamat di Jl. MT Haryono No 55 Malang.

3. Toko ketiga beralamat di Jl. Raya Sawangan No 45 Depok.

\subsection{Hasil Penelitian}

\subsubsection{Gambaran Umum Responden}

\section{Penelitian}

Responden dalam penelitian ini adalah konsumen Distro Club Kota Bogor yang berjumlah 100 orang. Responden yang dominan melakukan pembelian di Distro Club Kota Bogor adalah berdasarkan jenis kelamin yaitu laki-laki sebanyak 82 orang, berdasarkan usia 16-20 tahun sebanyak 49 orang, berdasarkan jenis pekerjaan pelajar/mahasiswa sebanyak 68 orang dan berdasarkan melakukan pembelian $>2$ kali sebanyak 64 orang.

\subsection{Uji Alat Ukur}

\subsubsection{Hasil Uji Validitas}

Uji Validitas digunakan untuk mengukur sah (valid) atau tidaknya suatu kuesioner.

\section{Tabel 4. Hasil Uji Validitas}

\begin{tabular}{|c|c|c|c|}
\hline Indikator & r hitung & r tabel & Keterangan \\
\hline Produk (X1) & & & \\
\hline X1.1 & 0,662 & 0,1966 & Valid \\
\hline X1.2 & 0,760 & 0,1966 & Valid \\
\hline X1.3 & 0,661 & 0,1966 & Valid \\
\hline X1.4 & 0,656 & 0,1966 & Valid \\
\hline Harga (X2) & & & \\
\hline X2.1 & 0,677 & 0,1966 & Valid \\
\hline X2.2 & 0,553 & 0,1966 & Valid \\
\hline X2.3 & 0,794 & 0,1966 & Valid \\
\hline X2.4 & 0,539 & 0,1966 & Valid \\
\hline Lokasi (X3) & & & \\
\hline X3.1 & 0,666 & 0,1966 & Valid \\
\hline X3.2 & 0,654 & 0,1966 & Valid \\
\hline X3.3 & 0,759 & 0,1966 & Valid \\
\hline X3.4 & 0,691 & 0,1966 & Valid \\
\hline Promosi (X4) & & & \\
\hline X4.1 & 0,819 & 0,1966 & Valid \\
\hline X4.2 & 0,807 & 0,1966 & Valid \\
\hline X4.3 & 0,533 & 0,1966 & Valid \\
\hline X4.4 & 0,449 & 0,1966 & Valid \\
\hline Keputusan & & & \\
\hline & & & \\
\hline
\end{tabular}

\begin{tabular}{|c|c|c|c|}
\hline $\begin{array}{c}\text { Pembelian } \\
(Y)\end{array}$ & & & \\
\hline Y1.1 & 0,767 & 0,1966 & Valid \\
\hline Y1.2 & 0,676 & 0,1966 & Valid \\
\hline Y1.3 & 0,642 & 0,1966 & Valid \\
\hline Y1.4 & 0,620 & 0,1966 & Valid \\
\hline
\end{tabular}

\subsubsection{Uji Reliabilitas}

Uji reliabilitas dilakukan dengan tujuan untuk mengetahui dari instrumen sebagai alat ukur, sehingga hasil suatu pengukurannya dapat dipercaya.

\section{Tabel 5. Hasil Uji Realibilitas}

\begin{tabular}{|c|c|c|}
\hline Variabel & $\begin{array}{c}\text { Nilai } \\
\text { Cronbach's } \\
\text { Alpha }\end{array}$ & Keterangan \\
\hline Produk (X1) & 0,616 & Reliabel \\
\hline Harga (X2) & 0,525 & Cukup Reliabel \\
\hline Lokasi (X3) & 0,630 & Reliabel \\
\hline Promosi (X4) & 0,593 & Cukup Reliabel \\
\hline $\begin{array}{c}\text { Keputusan } \\
\text { Pembelian (Y) }\end{array}$ & 0,599 & Cukup Reliabel \\
\hline
\end{tabular}

Sumber : Data primer yang diolah, 2018.

\subsection{Uji Normalitas Data}

\subsubsection{Uji Normalitas Plot}

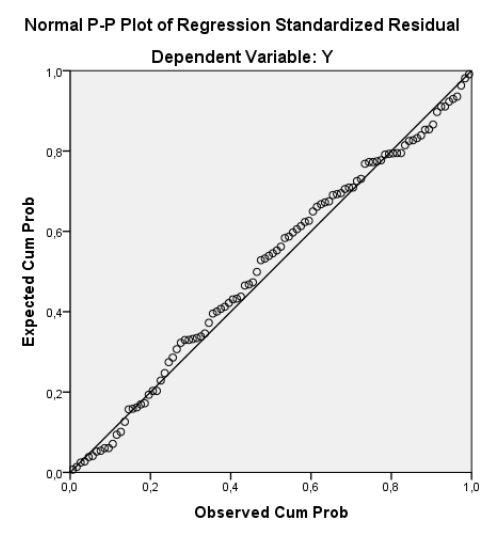

Gambar 2. Uji Grafik Scatter Plot

Sumber : Data primer yang diolah, 2018

Berdasarkan gambar diatas, deteksi normalitas data dapat dilihat dari penyebaran titik-titik pada garis diagonal dari grafik. Dalam grafik terlihat data menyebar di sekitar garis diagonal dan mengikuti arah garis diagonal. Dengan 
demikian, maka model dalam penelitian ini sudah memenuhi asumsi normalitas atau layak untuk digunakan.

\subsubsection{Uji Normalitas Kolmogorov Smirnov}

Tabel 6. Hasil Uji Normalitas Data

\begin{tabular}{|ll|r|}
\hline \multicolumn{2}{|c|}{ One-Sample Kolmogorov-Smirnov Test } \\
\hline & & $\begin{array}{r}\text { Unstandardized } \\
\text { Residual }\end{array}$ \\
\hline N & Mean & 100 \\
Normal Parameters ${ }^{\text {a,b }}$ &, 0000000 \\
& Std. & 1,46738546 \\
& Deviation &, 059 \\
Most Extreme Differences & Absolute &, 043 \\
& Positive &,- 059 \\
Test Statistic & Negative &, 059 \\
Asymp. Sig. (2-tailed) & &, $200^{\text {c, },}$ \\
\hline
\end{tabular}

a. Test distribution is Normal.

b. Calculated from data.

c. Lilliefors Significance Correction.

d. This is a lower bound of the true significance.

Dari hasil perhitungan uji Kolmogorov-Smirnov, maka dapat diketahui bahwa apabila Signifikansi (Asymp.sig) > 0,05 maka data berdistribusi normal, dan sebaliknya apabila Signifikansi (Asymp.sig) < 0,05 maka data tidak berdistribusi normal. Pada output data tabel di atas dapat diketahui bahwa apa nilai Asymp. Sig. (2-tailed) sebesar 0,200. Dengan demikian maka dapat dinyatakan berdistribusi normal.

\subsubsection{Uji Heteroskedastisitas}

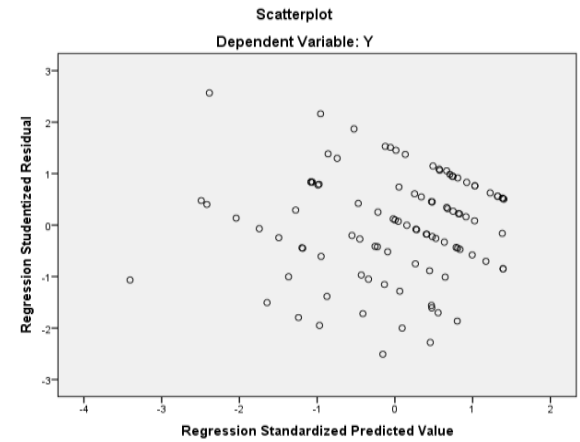

Gambar 3. Hasil Uji Heterokedastisitas
Dari gambar di atas dapat dilihat dari gambar diatas, bahwa titik menyebar dan tidak berbentuk pola, artinya pengujian inin bebas dari heteroskedastisitas.

\subsubsection{Uji Multikolinearitas}

Uji Multikolinearitas dilakukan untuk menguji apakah terdapat gejala korelasi diantara variabel independen dalam suatu model regresi. Suatu model regresi yang baik akan bebas dari Multikolinearitas dengan melihat nilai Tolerance dan Inflation Factor (VIF) pada model regresi.

Model dinyatakan bebas dari ganguan Multikolinearitas jika mempunyai nilai tolerance $>$ dari 0,1 atau nilai VIF $<10$.

Tabel 7. Hasil Uji Multikolinearitas

\begin{tabular}{|c|c|c|l|}
\hline \multirow{2}{*}{ Variabel } & \multicolumn{2}{|c|}{ Colinearity Statistics } & \multirow{2}{*}{ Keteragan } \\
\cline { 2 - 3 } & Tolerance & VIF & \\
\hline X1 & 0,575 & 1,740 & $\begin{array}{l}\text { Bebas } \\
\text { Multikolinearitas }\end{array}$ \\
\hline X2 & 0,436 & 2,292 & $\begin{array}{l}\text { Bebas } \\
\text { Multikolinearitas }\end{array}$ \\
\hline X3 & 0,709 & 1,411 & $\begin{array}{l}\text { Bebas } \\
\text { Multikolinearitas }\end{array}$ \\
\hline X4 & 0,574 & 1,743 & $\begin{array}{l}\text { Bebas } \\
\text { Multikolinearitas }\end{array}$ \\
\hline
\end{tabular}

Sumber : Data primer yang diperoleh, 2018.

Dari hasil uji Multikolinearitas diatas, semua nilai tolerance variabel independen > dari 0,1 atau nilai VIF < dari 10 yang mengindikasikan tidak terjadinya Multikolinearitas.

\subsection{Uji Korelasi}

Uji korelasi digunakan untuk mengetahui apakah ada hubungan antara dua variabel, dalam hal ini adalah variabel terikat dan variabel bebas. 
Tabel 8. Hasil Uji Korelasi

\begin{tabular}{|c|c|c|c|c|c|c|}
\hline \multicolumn{7}{|c|}{ Correlations } \\
\hline & & \begin{tabular}{|l|} 
Keputusan \\
Pembelian
\end{tabular} & Produk & Harga & Lokasi & Promosi \\
\hline \multirow{3}{*}{$\begin{array}{l} \\
\text { Keputusan } \\
\text { Pembelian }\end{array}$} & \multirow{3}{*}{$\begin{array}{l}\text { Pearson } \\
\text { Correlatio } \\
\text { Sig. (2- } \\
\text { tailed) } \\
\mathrm{N}\end{array}$} & 1 &, $528^{* *}$ &, $470^{\circ}$ &, $292^{\circ}$ &, $401^{\circ \prime}$ \\
\hline & & & 0 & 0 & 0,003 & 0 \\
\hline & & 100 & 100 & 100 & 100 & 100 \\
\hline \multirow{3}{*}{ Produk } & \multirow{3}{*}{$\begin{array}{l}\text { Pearson } \\
\text { Correlatio } \\
\text { Sig. (2- } \\
\text { tailed) } \\
\mathrm{N}\end{array}$} &, $528^{\circ 1}$ & 1 &, $612^{\circ *}$ &, $429^{\circ \prime}$ &, $523^{\circ "}$ \\
\hline & & 0 & & 0 & 0 & 0 \\
\hline & & 100 & 100 & 100 & 100 & 100 \\
\hline \multirow{3}{*}{ Harga } & \multirow{3}{*}{$\begin{array}{l}\text { Pearson } \\
\text { Correlatio } \\
\text { Sig. (2- } \\
\text { tailed) } \\
\mathrm{N}\end{array}$} &, $470^{\circ}$ & ,612" & 1 &, $517^{\circ}$ &, $626^{\circ \prime}$ \\
\hline & & 0 & 0 & & 0 & 0 \\
\hline & & 100 & 100 & 100 & 100 & 100 \\
\hline \multirow{3}{*}{ Lokasi } & \multirow{3}{*}{$\begin{array}{l}\text { Pearson } \\
\text { Correlatio } \\
\text { Sig. (2- } \\
\text { tailed) } \\
\mathrm{N}\end{array}$} & , $292^{\circ *}$ & ,429" &, $517^{\circ}$ & 1 &, $307^{\circ}$ \\
\hline & & 0,003 & 0 & 0 & & 0,002 \\
\hline & & 100 & 100 & 100 & 100 & 100 \\
\hline \multirow{3}{*}{ Promosi } & \multirow{3}{*}{$\begin{array}{l}\text { Pearson } \\
\text { Correlatio } \\
\text { Sig. (2- } \\
\text { tailed) } \\
\mathrm{N}\end{array}$} &, $401^{\prime \prime}$ &, $523^{* *}$ &, $626^{\circ \prime}$ &, $307^{\prime \prime}$ & 1 \\
\hline & & 0 & 0 & 0 & 0,002 & \\
\hline & & 100 & 100 & 100 & 100 & 100 \\
\hline
\end{tabular}

**. Correlation is significant at the 0.01 level (2-tailed).

Sumber : Data primer yang diolah, 2018.

Berdasarkan hasil uji korelasi diatas dapat dijelaskan sebagai berikut:

1. Nilai korelasi untuk variabel produk dengan keputusan pembelian adalah sebesar 0,528 yang artinya sedang. Hal ini menunjukan bahwa hubungan antara produk dengan keputusan pembelian berada pada tingkat sedang 0,528 .

2. Nilai korelasi untuk variabel harga dengan keputusan pembelian adalah sebesar 0, 470 yang artinya sedang. Hal ini menunjukan bahwa hubungan antara harga dengan keputusan pembelian berada pada tingkat sedang 0,470 .

3. Nilai korelasi untuk variabel lokasi dengan keputusan pembelian adalah sebesar 0, 292 yang artinya rendah. Hal ini menunjukan bahwa hubungan antara lokasi dengan keputusan pembelian berada pada tingkat rendah 0,292 .

4. Nilai korelasi untuk variabel promosi dengan keputusan pembelian adalah sebesar 0,401 yang artinya sedang. Hal ini menunjukan bahwa hubungan antara promosi dengan keputusan pembelian berada pada tingkat sedang 0,401 .

\subsection{Uji Koefisien Determinasi $\left(\mathbf{R}^{2}\right)$}

Tabel 9. Uji Koefisien Determinasi $\left(\mathbf{R}^{2}\right)$

\begin{tabular}{|c|c|c|c|}
\hline \multicolumn{4}{|c}{ Model Summary $^{\mathbf{b}}$} \\
$\mathrm{R}$ & $\begin{array}{c}\mathrm{R} \\
\text { Square }\end{array}$ & $\begin{array}{c}\text { Adjusted } \\
\text { R Square }\end{array}$ & $\begin{array}{c}\text { Std. Error } \\
\text { of the } \\
\text { Estimate }\end{array}$ \\
\hline, $564^{\mathrm{a}}$ & 0,318 & 0,29 & 1,49796 \\
\hline
\end{tabular}

a. Predictors: (Constant), X4, X3, X1, X2

b. Dependent Variable: Y

Sumber : Data primer yang diolah, 2018.

Hasil uji koefisien determinasi dapat diketahui diperoleh nilai Adjusted $\mathrm{R}^{2}$ sebesar 0,290, hal ini berarti 29,0\% keputusan pembelian di Distro Club Kota Bogor dipengaruhi oleh bauran pemasaran sedangkan sisanya $71,0 \%$ keputusan pembelian dipengaruhi oleh variabelvariabel lainnya yang tidak diteliti dalam penelitian ini. 


\subsection{Analisis Regresi Linier Berganda}

Tabel 10. Analisis Regresi Linier Berganda

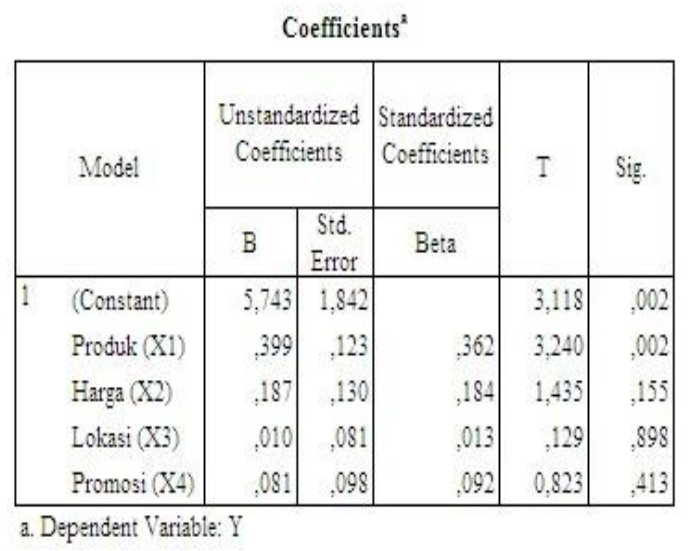

Sumber : Data primer yang di olah, 2018.

Berdasarkan hasil uji regresi linier berganda diatas dapat diperoleh persamaan regresi dengan rumus yaitu sebagai berikut:

$$
\begin{aligned}
& \mathrm{Y}=\mathrm{a}+\mathrm{b} 1 \mathrm{X} 1+\mathrm{b} 2 \mathrm{X} 2+\mathrm{b} 3 \mathrm{X} 3+\mathrm{b} 4 \mathrm{X} 4+ \\
& \mathrm{e} \\
& \mathrm{Y}=5,743+0,399 \mathrm{X} 1+0,187 \mathrm{X} 2+0,010 \\
& \mathrm{X} 3+0,081 \mathrm{X} 4
\end{aligned}
$$

Dari persamaan regresi tersebut dapat dijelaskan sebagai berikut:

1. Nilai konstanta 5,743 mempunyai arti bahwa jika tidak ada bauran pemasaran (produk, harga, lokasi dan promosi), maka keputusan pembelian akan konstan sebesar 5,743.

2. Nilai 0,399 , mempunyai arti bahwa jika terjadi kenaikan satuan nilai variabel bauran pemasaran dari indikator produk, maka akan meningkatkan nilai keputusan pembelian sebesar 0,399 satuan.

3. Nilai 0,187 , mempunyai arti bahwa jika terjadi kenaikan satuan nilai variabel bauran pemasaran dari indikator harga, maka akan meningkatkan nilai keputusan pembelian sebesar 0,187 satuan.

4. Nilai 0,010 , mempunyai arti bahwa jika terjadi kenaikan satuan nilai variabel bauran pemasaran dari indikator lokasi, maka akan meningkatkan nilai keputusan pembelian sebesar 0,010 satuan.

5. Nilai 0,081 , mempunyai arti bahwa jika terjadi kenaikan satuan nilai variabel bauran pemasaran dari indikator promosi, maka akan meningkatkan nilai keputusan pembelian sebesar 0,081 satuan.

\subsection{Uji Hipotesis}

\subsubsection{Uji Signifikansi Parsial (Uji t)}

Digunakan untuk menguji tingkat signifikan pengaruh variabel-variabel bebas terhadap variabel terikat secara terpisah. Untuk mencari $t$ tabel dapat dihitung dengan rumus sebagai berikut:

$$
\begin{aligned}
\alpha & =5 \% \\
\text { df } & =n-k \\
& =100-5=95
\end{aligned}
$$

Maka t tabel diketahui $t(95,0.05)=1,66$

Tabel 11. Hasil Uji Signifikansi Parsial (Uji t)

\begin{tabular}{|c|c|c|c|l|}
\hline Variabel & $\begin{array}{c}\mathbf{t} \\
\text { tabel }\end{array}$ & $\begin{array}{c}\mathbf{t} \\
\text { hitung }\end{array}$ & Sig. & Keputusan \\
\hline $\begin{array}{c}\text { Produk } \\
(\mathrm{X} 1)\end{array}$ & 1,66 & 3,240 &, 002 & $\begin{array}{l}\text { HO ditolak, } \\
\text { Ha diterima }\end{array}$ \\
\hline $\begin{array}{c}\text { Harga } \\
(\mathrm{X} 2)\end{array}$ & 1,66 & 1,435 &, 155 & $\begin{array}{l}\text { HO } \\
\text { diterima, } \\
\text { Ha ditolak }\end{array}$ \\
\hline $\begin{array}{c}\text { Lokasi } \\
(\mathrm{X} 3)\end{array}$ & 1,66 &, 129 &, 898 & $\begin{array}{l}\text { HO } \\
\text { diterima, } \\
\text { Ha ditolak }\end{array}$ \\
\hline $\begin{array}{c}\text { Promosi } \\
(\mathrm{X} 4)\end{array}$ & 1,66 &, 823 &, 413 & $\begin{array}{l}\text { HO } \\
\text { diterima, } \\
\text { Ha ditolak }\end{array}$ \\
\hline
\end{tabular}

Sumber : Data primer yang diolah, 2018

Untuk menguji model regresi untuk masing-masing variabel secara parsial dapat diperoleh dengan menggunakan uji t. Berikut akan dijelaskan pengujian masingmasing variabel secara parsial.

1. Nilai t-hitung untuk bauran pemasaran (produk) sebesar 3,240 > nilai t-tabel 1,66. Dengan nilai signifikansi sebesar $0,002<0,05$ nilai signifikansi yang lebih kecil dari 0,05 menunjukkan bahwa pada taraf signifikansi 5\% maka 
hipotesis $\mathrm{HO}$ ditolak dan Ha diterima. Artinya terdapat pengaruh yang signifikan antara bauran pemasaran (produk) dengan keputusan pembelian.

2. Nilai t-hitung untuk bauran pemasaran (harga) sebesar $1,435<$ nilai t-tabel 1,66. Dengan nilai signifikansi sebesar $0,155>0,05$ nilai signifikansi yang lebih besar dari 0,05 menunjukan bahwa pada taraf signifikansi 5\% maka hipotesis Ho diterima dan Ha ditolak. Artinya tidak terdapat pengaruh yang secara signifikan antara bauran pemasaran (harga) dengan keputusan pembelian.

3. Nilai t-hitung untuk bauran pemasaran (lokasi) sebesar $0,129<$ nilai t-tabel 1,66. Dengan nilai signifikansi sebesar $0,898>0,05$ nilai signifikansi yang lebih besar dari 0,05 menunjukan bahwa pada taraf signifikansi 5\% maka hipotesis Ho diterima dan Ha ditolak. Artinya tidak terdapat pengaruh yang secara signifikan antara bauran pemasaran (lokasi) dengan keputusan pembelian.

4. Nilai t-hitung untuk bauran pemasaran (promosi) sebesar 0,823 < nilai t-tabel 1,66. Dengan nilai signifikansi sebesar $0,413>0,05$ nilai signifikansi yang lebih besar dari 0,05 menunjukan bahwa pada taraf signifikansi 5\% maka hipotesis HO diterima dan Ha ditolak,. Artinya tidak terdapat pengaruh yang secara signifikan antara bauran pemasaran (promosi) dengan keputusan pembelian.

Dari hasil uji hipotesis di atas dapat diketahui bahwa faktor yang mempengaruhi keputusan pembelian konsumen pada Distro Club Kota Bogor adalah hanya satu variabel yaitu variabel Produk sebesar 3,240. Hal ini sesuai dengan konsep distro yang menjual produk yang memiliki keunikan dan perbedaan tersendiri diatara produk pada umum nya yang biasa kita jumpai di pasar tradisional maupun pasar swalayan atau mall.

\subsubsection{Uji Signifikansi Simultan (Uji F)}

Tabel 12. Hasil Uji Signifikansi Simultan (Uji F)

\begin{tabular}{|rl|r|r|r|c|c|}
\multicolumn{8}{|c|}{ ANOVA $^{2}$} \\
\hline & Model & $\begin{array}{r}\text { Sum of } \\
\text { Squares }\end{array}$ & Df & $\begin{array}{l}\text { Mean } \\
\text { Square }\end{array}$ & F & Sig. \\
\hline 1 & Regression & 99,581 & 4 & 24,895 & 11,095 &, $000^{\circ}$ \\
& Residual & 213,169 & 95 & 2,244 & & \\
Total & 312,75 & 99 & & & \\
\hline
\end{tabular}

a. Dependent Variable: Y

b. Predictors: (Constant), X4, X3, X1, X2

Sumber : Data primer yang diolah, 2018

Untuk menentukan nilai $\mathrm{F}$, maka diperlukan adanya derajat bebas pembilang dengan derajat bebas penyebut, dengan rumus sebagai berikut:

$$
\begin{aligned}
\text { Df1 } & =\mathrm{k}-1 \\
& =5-1=4 \\
\text { Df } 2 & =\mathrm{n}-\mathrm{k} \\
& =100-5=95
\end{aligned}
$$

Maka $\mathrm{f}$ tabel diketahui $\mathrm{t}(95,4)=2.47$

Nilai Fhitung akan diperoleh dengan menggunakan bantuan sofware SPSS, kemudian akan dibandingkan dengan nilai F tabel pada tingkat $\alpha=5 \%$

H0 diterima jika Fhitung $<$ Ftabel pada $\alpha=$ $5 \%$

H0 ditolak jika Fhitung $>$ Ftabel pada $\alpha=$ $5 \%$

Pengujian pengaruh variabel bebas secara bersama-sama terhadap variabel terikatnya dilakukan dengan menggunakan uji F. Hasil perhitungan statistik menunjukan nilai $\mathrm{F}$ hitung $=11,095$ dengan signifikansi sebesar $0,000<0,05$. Dengan nilai signifikansi dibawah 0,05 dan nilai $\mathrm{F}$ hitung $(11,095)>F$ tabel $(2,47)$ menunjukan bahwa secara bersama-sama faktor produk, harga, lokasi dan promosi mempunyai pengaruh yang positif dan signifikan terhadap keputusan pembelian konsumen pada Distro Club di Kota Bogor. 
5. KESIMPULAN DAN SARAN

\subsection{Kesimpulan}

Berdasarkan hasil penelitian yang telah diuraikan maka kesimpulan dalam penelitian ini adalah:

1. Berdasarkan hasil penelitian variabel produk (X1) berpengaruh signifikan dan positif dengan nilai t-hitung untuk bauran pemasaran (produk) sebesar $3,240>$ nilai t-tabel 1.66. Dengan nilai signifikansi sebesar $0,002<0,05$ nilai signifikansi yang lebih kecil dari 0,05 menunjukkan bahwa pada taraf signifikansi 5\% maka hipotesis yang menyatakan bahwa produk memiliki pengaruh positif terhadap keputusan pembelian konsumen pada Distro Club Kota Bogor.

2. Berdasarkan hasil penelitian variabel harga (X2) tidak terdapat pengaruh yang signifikan dengan nilai t-hitung untuk bauran pemasaran (harga) sebesar $1,435<$ nilai t-tabel 1.66. Dengan nilai signifikansi sebesar 0,155 $>0,05$ nilai signifikansi yang lebih besar dari 0,05 menunjukan bahwa pada taraf signifikansi 5\% maka tidak terdapat pengaruh yang secara signifikan antara bauran pemasaran (harga) dengan keputusan pembelian konsumen Distro Club Kota Bogor.

3. Berdasarkan hasil penelitian variabel lokasi (X3) tidak terdapat pengaruh yang signifikan dengan nilai t-hitung untuk bauran pemasaran (lokasi) sebesar $0,129<$ nilai t-tabel 1.66 . Dengan nilai signifikansi sebesar 0,898 $>0,05$ nilai signifikansi yang lebih besar dari 0,05 menunjukan bahwa pada taraf signifikansi 5\% maka tidak terdapat pengaruh yang secara signifikan antara bauran pemasaran (lokasi) dengan keputusan pembelian Distro Club Kota Bogor.

4. Berdasarkan hasil penelitian variabel promosi (X4) tidak terdapat pengaruh yang signifikan dengan nilai t-hitung untuk bauran pemasaran (promosi) sebesar 0,823 < nilai t-tabel 1.66. Dengan nilai signifikansi sebesar 0,413 $>0,05$ nilai signifikansi yang lebih besar dari 0,05 menunjukan bahwa pada taraf signifikansi 5\% maka tidak terdapat pengaruh yang secara signifikan antara bauran pemasaran (promosi) dengan keputusan pembelian Distro Club Kota Bogor.

5. Secara simultan produk, harga, lokasi dan promosi berpengaruh signifikan terhadap keputusan pembelian konsumen. Hal ini mengindikasikan bahwa keputusan pembelian konsumen ditentukan dengan produk, harga, lokasi dan promosi secara bersamasama. Hal ini dapat dilihat pada hasil uji $f$ dengan menggunakan taraf signifikansi 0,05 diperoleh $\mathrm{F}$ hitung sebesar 11,095dengan $F$ tabel sebesar 2.47 dengan demikian $\mathrm{F}$ hitung $>\mathrm{F}$ tabel dengan tingkat signifikansi yang diperoleh $0,000<0,05$.

\subsection{Saran}

Dari hasil penelitian dapat diketahui bahwa saran yang dapat diberikan dalam penelitian ini yaitu:

1. Perlu mempertahankan produk agar kepercayaan konsumen agar tetap melakukan pembelian di Distro Club Kota Bogor.

2. Perlu meningkatkan Produk (kualitas produk, daya tahan produk, kesesuaian produk dengan spesifikasi, estetika atau tampilan produk. Untuk mempertahankan dan meningkatkan konsumen agar tetap melakukan pembelian di Distro Club Kota Bogor.

\section{DAFTAR PUSTAKA}

Alma, Buchari, 2004. Manajemen Pemasaran dan Pemasaran Jasa. Bandung, Alfabeta.

Andini P.F, 2013. Analisis Pengaruh Suasana Toko, Kualitas Produk dan Kepuasan Pelanggan terhadap loyalitas 
pelanggan (studi pada konsumen

Distro Deep Store di Surakarta).

Skripsi, Universitas Diponogoro

Semarang.

Distro Club. 2015-2017, Data Internal Penjualan.Bogor.

Fatimah S,2017. Analisis Pengaruh Bauran Pemasaran (Marketing Mix) Terhadap Tingkat Kunjungan Pemakai Jasa Pada PT Putra Sentra Prasarana (Permata Sentul Golf Bogor). Skripsi, STIE Dewantara.

Ferania I, 2017. Pengaruh Bauran Pemasaran Terhadap Keputusan Masyarakat Berbelanja Di Pasar Rakyat Cibinong Kabupaten Bogor, Skripsi, STIE Dewantara..

Ghozali, Imam, 2005. Aplikasi Analisis Multivariate dengan Program SPSS. Edisi Kedua. Badan Penelitian Universitas Diponogoro, Semarang.

Handoko, Hani.2000. Manajemen Pemasaran, Analisa Prilaku Konsumen. BPFE- Yogyakarta, Yogyakarta.

Kotler \& Amstrong, 2008. Prinsip-prinsip Pemasaran. Jilid 1, (Alih Bahasa: Bob Sabran, M,M), Penerbit Erlangga Jakarta.

Kotler, Philip dan Kaller, 2010. Manajemen Pemasaran. Jilid 1, Edisi Ketiga Belas, Erlangga, Jakarta. 